\title{
Peculiarities of Dissinchrony in the Intellectually Gifted 7-Year-Old Children
}

\author{
Tatyana Bashkireva ${ }^{1, a}$, Anastasia Bashkireva ${ }^{1, b}$, Alexander Morozov²,c* \\ 1 Ryazan State University named for S. A. Yesenin, 390000, 46 Svobody str., Ryazan, Russia \\ 2 Institute of Education Management of the Russian Academy of Education, 105062, 16 Zhukovsky \\ str., Moscow, Russia \\ abashkirevat@bk.ru, bbashkireva32@gmail.com, doc_morozov@mail.ru \\ ${ }^{*}$ Corresponding author
}

\begin{abstract}
Keywords: children, intellectually gifted, dyssynchrony, physical development, mental development, adaptation, training, child, abilities, talent, intellect, makings

Abstract : The article discusses the issues of dyssynchrony in the intellectually gifted seven-year-old children. The results of the study show that in children of the designated age category, mental and physical development are interrelated, which coincides with previously published scientific data. In artistic gifted boys and girls, a high level of physical development coincides with a mental one, which testifies to the age giftedness. Musically gifted boys and girls have a dyssynchronism between physical and mental development. The obtained data on the physical development and functional maturity of the examined people confirm the presence of dyssynchronism in both children with a high level of abilities and intellectually gifted children. Based on the obtained empirical data, it can be argued that the above phenomenon is characterized by various mechanisms that increase the resistance of the growing organism to the factors that negatively affect it.
\end{abstract}

\section{Relevance}

The modern education being built on the formation of a knowledge algorithm, in which such a form of control as pedagogical testing dominates, negatively affects the intellectual development of children. In this regard, many modern parents seek to identify children in institutions/organizations of additional education, which would contribute to the physical, intellectual development of children and in the future could contribute to a satisfactory biological and social adaptation to systematic education. It is in such organizations that a high level of inclinations is found in various areas of activity, which, when being organized in their development, are noted as a high level of ability or talent.

In the scientific literature there are different opinions in the use of the definitions of "giftedness" or "gifted children" [5]. The most accessible study of intellectual abilities and talent allows to correctly apply these concepts. However, a number of problems are also noted here, which consists in the lack of valid methods [4]. The techniques concern general intelligence, but there are children whose interests lie in other areas not covered by widely used intelligence tests. And in this case, these children fall out of sight of researchers, educators, and psychologists.

Analysis of literary sources shows that among the intellectually capable children there are two groups:

1. Educational and communicative success coincides with a high level of intelligence;

2. A high level of intelligence does not provide educational and communicative success.

In connection with the conditional division of intellectually capable children into two groups indicated by us above, either a high level of abilities or endowments are available to the society. The second group of children, more often defined as being not successful, is of particular interest, because the area of their intellectual capabilities was out of focus.

It is known that the concept of "developmental dyssynchrony" is widely used in foreign and Russian psychological studies of talent. The essence of this concept is that with the advanced development of individual functions, gifted children can concede in others to their peers [6]. This problem is relevant due to the fact that some intellectually gifted children have a poor development of fine motor skills, as a result of 
which they are among students with a low level of academic success [6]. Researchers note that these children have a reduced learning motivation, loose interest in school, distance themselves in school groups, and are often not successful [1,10]. In some works, it is noted that the success of learning cannot be identified with school grades; however, performance affects the psycho-emotional sphere of a gifted child $[3,8]$.

The purpose of the empirical study conducted by us was to study the characteristics of dysynchrony in the intellectually gifted seven-year-old children of seven years of age.

\section{Research methods}

To identify a group of intellectually gifted children, the technique used by P. Torrens "Finish the drawing" [7] was used.

Also we studied:

1) Physical development (body length - L; body weight - m; weight-height index - ARI);

2) Self-typing [2];

3) Body mass index (BMI - development of the fat layer, consistent with nutritional data) [11];

4) The level of functional maturity and readiness for systematic training (Kern-Jirasek technique) [9].

To achieve the goal, 139 seven-year-old children (boys - 64; girls - 75)studying at the centers for the development of musical and artistic abilities were surveyed. Among the surveyed were selected:

1) A control group of children who drew the proposed figures, but did not tie them into the picture, although they showed a high level in music and art classes; we called them "capable" (78 children: 36 boys; 42 girls);

2) A group of children who were also successful in music and artistic classes and had no issues with drawing and composing the history of pictures from the proposed figures, in accordance with the technique of P. Torrens. We called such children as "intellectually gifted" (the total number of children in the group was 61: 28 boys and 33girls).

The second group was divided into two subgroups:

1) Children with a high level of artistic ability - "artistically gifted" (12 boys, 10 girls);

2) Children with a high level of musical ability - "musically gifted" (16 boys, 23 girls).

\section{Research results}

The physical development of a child is an external integral manifestation of the adequacy of the processes of growth and development to the conditions of existence of the organism. In the case of a significant deviation from the standards, we can speak of violations of growth rates and physical development. The pace of physical development is an important characteristic of the health of a growing organism. According to researchers, the level of physical development reflects not only the degree of functional maturity, but also the rate of mental development.

Analysis of the obtained data on physical development showed a lack of body weight in all the examined children.

The intellectually gifted boys $(\mathrm{t}=3.04 ; \mathrm{P}<0.05)$ and girls $(\mathrm{t}=4.28 ; \mathrm{P}<0.001)$ are significantly higher than their peers in the control group.

The breast circumference in artistically gifted girls is significantly greater $(\mathrm{t}=5.0-4.8 ; \mathrm{P}<0.001)$ than musically gifted and control groups. 

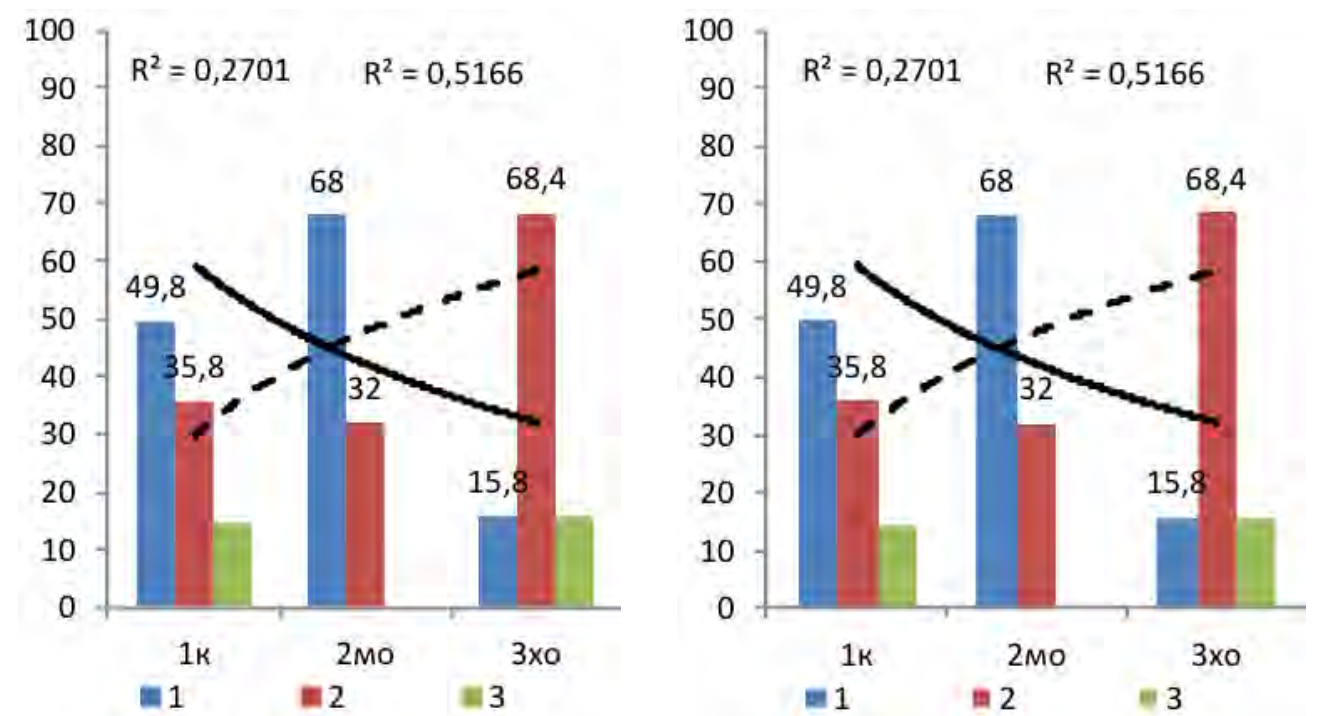

Fig.1. The physical development of 7-year-old children of the control and intellectually gifted groups (reliability of the trend line in the logarithmic approximation).

Note:

I. The level of harmonious development: 1 - harmonious; 2 - disharmonious; 3 - sharply disharmonious;

II. Their somatotype: 1 - microsomatotype; 2 - mesosomatic type; 3 - macrosomatotype;

$1 \mathrm{k}$ - control group; 2 mo - musically gifted; 3xo - artistically gifted.

The analysis of our results, presented graphically in Fig.1 (see histogram I), allow us to conclude that growth processes are synchronized in three groups of children (harmonious, disharmonious, and sharply disharmonious) both in the control group and intellectually gifted in terms of body mass deficiency. It is known that with a half-growth jump, children lose weight which affects physical development in general. This phenomenon of asynchrony is explained by age-related physiological features.

In Fig. 1, the histogram II is of particular interest, which shows the somatotypes of all three groups of children. In accordance with the trend line in the logarithmic approximation, there is a cross-adaptation of the auto-types, characterized by sensitivity to one stimulus, but increased resistance to the effects of others. Thus, the highest percentage of the microsomatotype was found for the musically gifted; and for the artistically gifted boys and girls was found the macrosomatotype. Cross-adaptation in the musically gifted children can be explained by high sensitivity to the development of musical hearing, which can cause resistance to other external and internal stimuli and restrain, for example, the development of weight-growth processes.

In the artistically gifted children, the development of fine motor skills, activates overall motor responses, including indicators of physical development.

It is known that children differ in terms of the onset and degree of sensitivity, which can affect the course of development of their abilities and talents. The functional maturity (Kern-Jirasek technique) was studied in the study groups.

It was revealed that $25.5 \%$ of the musically gifted children and $89.5 \%$ of the artistically capable children are mature and have a high level of readiness for systematic learning, these differences are significant $(\mathrm{t}=4.698 ; \mathrm{P}<0.001)$. The average matured were respectively $53 \% \div 10.5 \%$.

In the artistically capable children, a correlation was established between physical development and high maturity of functional systems and readiness for systematic learning $(\mathrm{r}=2.03 ; \mathrm{P}<0.001)$.

In musically gifted children, physical development indicators correlate with indicators of medium maturity and readiness for systematic training $\left(v=5 ; \chi^{2}=20,063 ; \mathrm{P}<0,001\right)$.

A high level of functional maturity to systematic learning has been identified in artistically gifted boys 
and girls $(89,5 \%)$.

The majority of children in the control sample (64.2\%) and the musically gifted ones (53\%) showed an average level of functional maturity of the brain.

$68 \%$ of the musically capable and $100 \%$ of the artistically gifted children showed positive motivation to learn.

A sharply negative attitude towards the learning process was observed in $4 \%$ of musically capable children.

The results of physical development obtained by us confirm the previously published scientific data on the dyssynchrony of the development of gifted children.

The analysis of the relationship of individual indicators of physical development with scales according to the method of P. Torrens was conducted.

So, the artistically gifted boys revealed a significant relationship between weight-height indicators and creative abilities $(\rho=0,533 ; p<0,01)$.

The boys revealed a positive significant relationship between "weight" and "originality" ( $\rho=0,42$; $\mathrm{P}<0,05)$.

The weight-growth index of intellectually gifted children reliably affects: "fluency" $(\rho=0,72 ; P<0,001)$ and "originality" of the performing tasks $(\rho=0,707 ; \mathrm{P}<0,001)$.

We also revealed a high relationship between physical development and creativity in the artistically gifted boys and girls. It is likely that this fact is due to the fact that at the age of seven years, children experience a quite dynamic biological maturation associated with a half-growth jump, which affects the mental development, which can be called "age talent."

The obtained empirical results also led to the conclusion that in boys, their biological maturation affects mental development and the emergence of age endowments. In girls, most likely, a different mechanism of the appearance of age giftedness is involved.

Thus, in the artistic gifted boys and girls, a high level of physical development coincides with the mental one, which indicates their age giftedness.

Musically gifted boys and girls have a dyssynchrony between physical and mental development.

\section{Conclusion}

The empirical data obtained by us regarding the physical development and functional maturity of the examined people confirm the presence of dyssynchronism in both children with a high level of ability and intellectually gifted. However, this phenomenon has different mechanisms and, we believe, in general, increases the resistance of the growing organism to negatively affecting factors.

\section{Acknowledgments}

The article was prepared in the framework of the implementation of the State task of the Ministry of Education and Science of Russia for 2018 on the topic №27.9385.2017/БЧ “Theoretical and methodological foundations of the professional development of education system managers".

\section{References}

[1] Bashkireva, T. V. (2009). Psychological and pedagogical search, 3(11), pp. 131-138.

[2] Bezrukikh, M. M., Sonkin, V. D., \& Farber, D. A. (2002). Developmental physiology (Physiology of child development). Moscow, Russia: Academy.

[3] Valueva, E. A., Grigoriev, A. A., \& Ushakov, D. V. (2015). Psychological Journal, 5(36), pp. 55-63.

[4] Morozov, A. V. (2001). Diagnostics of creativity in teaching. Moscow, Russia: IGUMO. 
[5] Morozov, A. V., \& Prutkaya, O. E. (2017). Formation of creativity in gifted children in the process of their creative learning in the system of modern education. In Problems of state, regional and municipal government at the present stage: Materials of the XII All-Russian Scientific Conference (pp. 13-17). Orenburg, Russia.

[6] Ushakov, D. V. (Ed.) (2000). Psychology of giftedness: From theory to practice. Moscow, Russia: IP RAS.

[7] Mironova, E. E. (Ed.) (2006). Collection of psychological tests. Part II: Manual. Minsk, Belarus: ENVILA Women's Institute.

[8] Sibgatullina, A. F. (2002). Dysynchrony of mental development of the intellectually gifted children and adolescents. Diss. ... Dr. Psych. Sciences. Sochi, Russia.

[9] Shvantsara, Y. (1978). Diagnosis of mental development. Prague, Czechoslovakia: Medical Publishing House Avincinnum.

[10] Scheblanova, E. I. (2018). Uneven development in the gifted children. Retrieved from http://psy.1september.ru/view_article.php?ID=200801804.

[11] E. N. Khrisanfova, \& Perevozchikov, L. V. (1991). Anthropology. Moscow, Russia: Publishing House of Moscow State University. 